\title{
Cambios en la vegetación en las montañas del noroeste de Guatemala de 1973 a 2016, de la guerra a la reposición
}

\section{Changes in vegetation in the mountains of northwestern Guatemala from 1973 to 2016, From war to replacement}

\author{
Como citar el artículo \\ Villavicencio, M., Vásquez, M. \& Parrot, J., (2019). Cambios en la vegetación en las montañas del noroeste de Gua- \\ temala de 1973 a 2016, de la guerra la oposición. Revista Naturaleza, Sociedad y Ambiente, 6 (1), 1-13 DOI: https:// \\ doi.org/10.37533/cunsurori.v6i1.37
}

Martha Eugenia Villavicencio Enríquez, Mario Vázquez Olivera \& Jean Francois Parrot

Centro Universitario de Sur Oriente (CUNSURORI), Universidad de San Carlos de Guatemala.

Recibido: 30 de agosto de 2019 / Aceptado: 20 de noviembre de 2019

Disponible en internet el 29 de noviembre de 2019

*Autor para correspondencia, correo electrónico: tlaxcale@gmail.com

\begin{abstract}
Resumen
El estudio de los cambios en la vegetación mediante el uso de índices Diferenciales de Vegetación Normalizados (NDVI, por sus iniciales en inglés) en dos grupos de datos general de 128-255 y 155-255 para vegetación más activa, presenta diferencias que pueden ser interpretadas en los cambios históricos regionales. Guerra, retorno de la población marcan a la vegetación del corte estudiado. Pero la marca no es solamente externa. La parcela ixil y su relación con el bosque dan forma al paisaje.
\end{abstract}

Palabras clave: vegetación agricultura ixil NDVI guerra

\section{Abstract}

Research on vegetation changes during the period from 1973 to 2016 using NDVI (Normalized Difference Vegetation Index) values within 128-255 and 155-255 for more active vegetation, shows differences which can be explained in the way of historical region processes. Because of the relation of ixil agriculture and forest, war and return of ixil population live a footprint on landscape.

Keywords: vegetation agriculture ixil NDVI war 


\section{Introducción}

Este trabajo explora la vegetación en una región montañosa, los Cuchumatanes en el noroeste de Guatemala, mediante el uso del índice normalizado de vegetación activa (NDVI por sus iniciales en inglés) para establecer una secuencia de cambios observables con las imágenes Landsat disponibles de 1973 hasta 2016.

Una segunda secuencia muestra que los cambios afectan a la vegetación más activa en forma diferente a los cambios generales. Las secuencias reflejan los cambios históricos en la región estudiada, que modificaron la vida del pueblo indígena ixil por la guerra de exterminio del gobierno guatemalteco, que impacta también a la vegetación. Al atacar a la cultura ixil que cultivaba y mantenía sus bosques, ocurren cambios comprobables mediante el uso de imagen remota en la vegetación considerada natural, que está unida al destino de las parcelas.

Este trabajo fue alojado por la Universidad Ixil con el acompañamiento de su Secretario Académico, Diego Santiago Ceto. Miguel Pérez Torres, traductor ixil-castellano, acompañó parte de las entrevistas. Los procesamientos fueron efectuados en el Laboratorio de
Análisis Geoespacial, Instituto de Geografía y el trabajo es parte de la tesis de doctorado de la primera autora en el Posgrado en Estudios Latinoamericanos de la UNAM en México. EI análisis histórico tuvo el apoyo del Seminario Guerra y Democracia en Centroamérica coordinado por el Dr. Mario Vázquez Olivera.

\section{El pueblo Ixil}

Es uno de los 22 pueblos aproximadamente, hablantes de idiomas mayenses que habitan Guatemala (Sistema de las Naciones Unidas en Guatemala, 2014, p. 17). Quiché tiene numerosos asentamientos ixiles que practican la agricultura campesina-indígena, con milpas intercaladas en superficies boscosas.

En todo el país el $70 \%$ de la población rural mayor de 15 se dedica a la agricultura. (Bouroncle, et al., 2015), podemos suponer por lo menos este porcentaje para las comunidades del área investigada. Hasta 2016, los datos gubernamentales apuntaban a que el $45 \%$ de las unidades de producción campesinas contaban con menos de una manzana de tierra, lo que equivale a un $3.4 \%$ de la tierra para sembrar. Mientras que 47 terratenientes poseen 4.71 de la tierra cultivable en propiedades de más de 50 caballerías o $35200 \mathrm{Ha}$. (MARN, 2017).

1 vara: $0.84 \mathrm{~cm}$

1 cuerda: es un cuadro de 25 varas por 25 varas o un cuadro de $21 \mathrm{~m}$ por $21 \mathrm{~m}$. O sea $441 \mathrm{~m} 2$

1 manzana: 16 cuerdas o $7056 \mathrm{~m} 2$

1 caballería: 1000 cuerdas. $44.1 \mathrm{Ha}$ 
La desposesión de las comunidades indígenas que ha llevado a conflictos que persisten hasta hoy. La pobreza asociada al acaparamiento de tierras afecta directa y sensiblemente a los pueblos indígenas.

La cultura ixil ha mantenido usos, que más allá de la sobrevivencia, se manifiestan tanto como conjuntos exitosos para garantizar la alimentación y el disfrute, como ambientalmente cuidadosos. La parcela da una impronta al paisaje del departamento de Quiché y una pequeña parte de Huehuetenango en nuestro corte de investigación.

Las historias personales de la población ixil están marcadas por los tiempos de persecución, guerra y reordenamiento del territorio efectuada por los gobiernos contrainsurgentes sucesivamente.

También es posible observar especialmente en el porcentaje en hectáreas que la vegetación ha tenido periodos de recuperación, que se relacionan con la población directamente, ya que la gente es propietaria de áreas de bosque y parcelas.
Es importante hacer notar que si bien hay descansos de las parcelas, en otros casos no los hay y la verificación In situ nos muestra que tienen décadas, generaciones, usando áreas parecidas para sembrar, antes y después del exilio y que usan pocos fertilizantes y agroquímicos.

Las parcelas tienen una inclinación grande, por lo que podría suponerse que el suelo estaría lavado, si bien es posible encontrar marcas de deslaves, lo que encontramos es un paisaje agrícola, con parcelas con plantas y árboles diversos parte de la dieta ixil, y bosques. En las observaciones fue posible entender que la parcela Ixil es un conjunto complejo que incluye no solamente la milpa con el grano básico maíz (Zea mais) y otras plantas asociadas, sino árboles, arbustos, tubérculos, con usos culturales como dieta, con algunas partes como un ever green.

El consumo de hojas, raíces, tallos, frutos en plantas como el uixkil (Sechium edule) que aunque presenta dormancia en invierno permanece verde, es emblemático. Ponemos a continuación el mosaico de la vegetación que presentan las montañas.

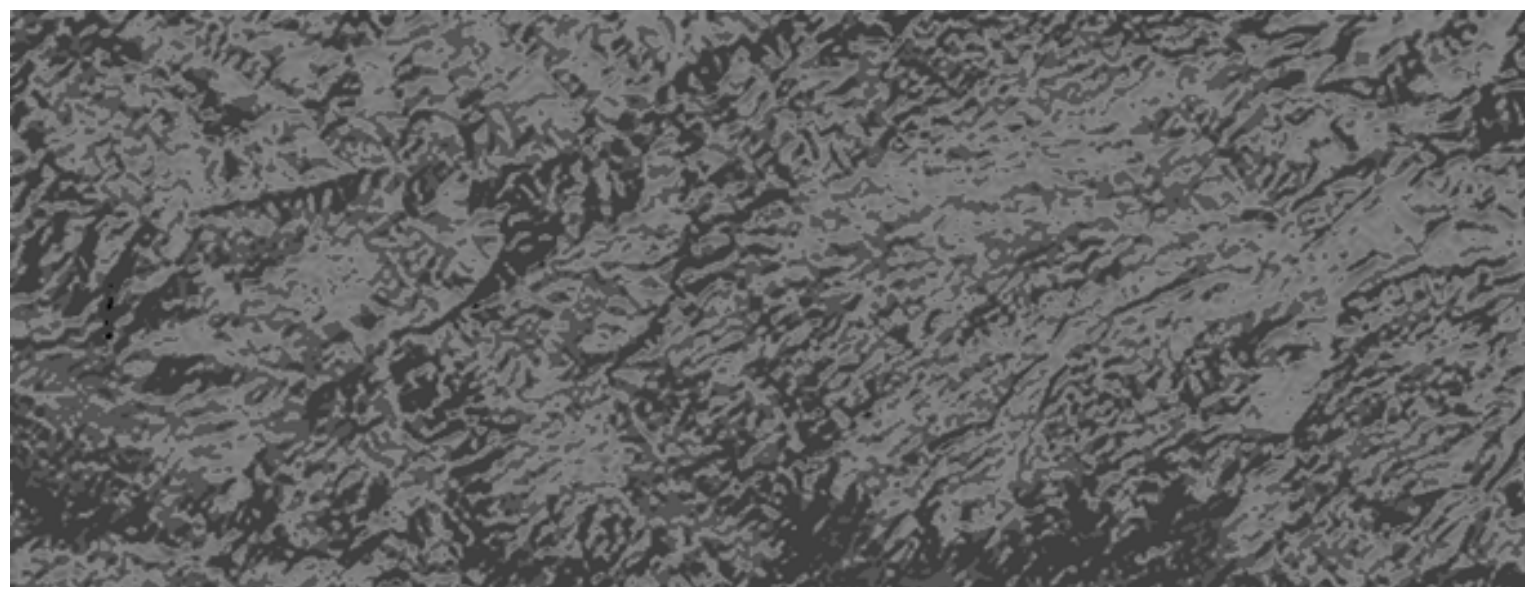

Figura 1. Dos estratos en la vegetación que muestran el mosaico continuo de milpas, poblaciones caminos y bosques. (Elaborados con el NDVI, uno que incluye todos los valores de vegetación activa de 128 a 255 en claro y otro que sólo toma en cuenta de 154 a 255 en oscuro en imagen de 1995 de nuestro corte. Imagen proporcionada por USGS, de la NASA de los EU. Procesamiento PINS_V2 (Parrot, 2011); Índices_V2 (Parrot, 2014) y Paintshop de Microsoft. 


\section{Medio físico estudiado}

Guatemala, Departamento Quiché, municipios de Nebaj, San Gaspar Chajul, y San Juan Cotzal. Una pequeña área al Oeste pertenece al Departamento Huehue- tenango. El corte que hicimos es un rectángulo cuya esquina noroeste se ubica con el Datum WGS 84, UTM Zona $15 \mathrm{~N}$, coordenadas Y 1716856 X683459; esquina sureste $Y 1700689 \times 722600$ (Figura 1).

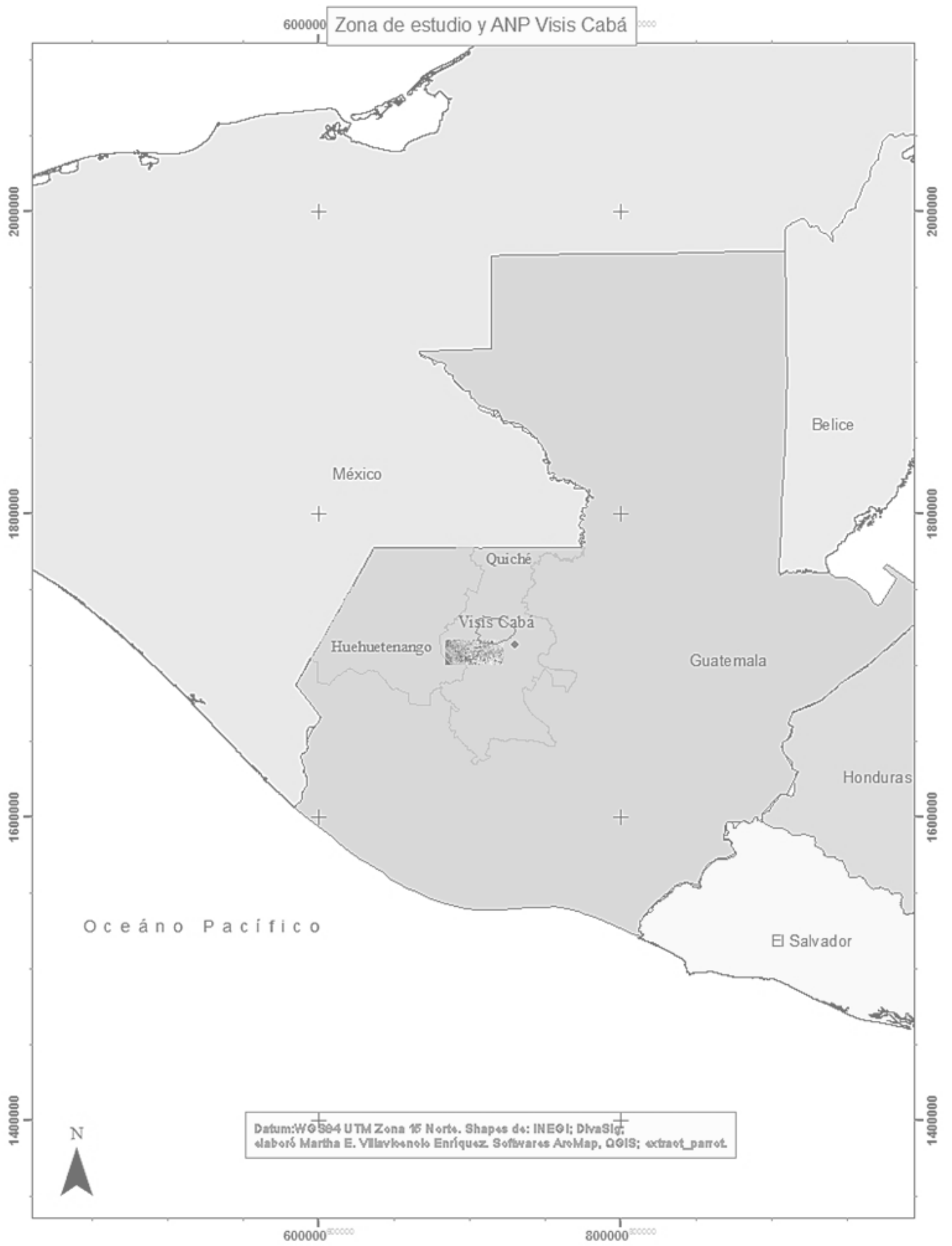

Figura 2. Mapa de la zona de estudio, elabora Martha E. Villavicencio E., software ArcMap ESRI. 
Son aproximadamente 64300 ha. Se incluye el traslape con el área Natural Protegida de Visis Cabá.

El área se ubica en las montañas Cuchumatanes, parte de un sistema montañoso que va de este a oeste del país (Organización de Estados Iberoamericanos para la educación, la ciencia y la cultura, s/f) Las altitudes investigadas fueron de los 2100 a los 3200 msnm aproximadamente. Las isoyetas medias anuales del Atlas hidrometeorológico ponen para nuestro corte solamente 1500 a $2000 \mathrm{~mm}$ lluvia anuales, al sur las isoyetas van desde 3000 a $4000 \mathrm{~mm}$. y disponibilidad media de agua (Instituto Nacional de Sismología, vulcanología, meteorología, e hidrología de Guatemala, s/f) Probablemente sea útil tomar los datos del lado mexicano para la región, que presentan efectivamente algunas zonas con precipitación baja hasta llegar a los $1000 \mathrm{~mm}$. Pero las franjas de precipitación alta van desde los 2500, 3000, 3500 y hacia el sur de la frontera con Guatemala alcanzan los $4000 \mathrm{~mm}$ de precipitación anual y van de NE a SO hacia Guatemala, acompañando a la Sierra Madre. México reporta también franjas contínuas de climas semi cálido húmedo con lluvias abundantes en verano; así como templado húmedo con lluvias abundantes en verano. La información de cuencas guatemalteca nos dice que las cuencas de este corte son Golfo de México 3.5 Ixcán con $5909 \mathrm{~mm}$ anuales; Golfo de México 3.6 Xaclbal con $3832 \mathrm{~mm}$ anuales de precipitación y Golfo de México 3.7 Salinas (Chixoy) cuya subcuenca Chixoy con precipitación máxima alcanza los $5295.6 \mathrm{~mm}$ (Saubes, et al., 2015).

Sobre la geología de la parte central norte, hay un basamento metamórfico e ígneo cubierto por capas rojas y por secuencias de carbonatos y evaporitas. (Empresa Propietaria de la
Red; Integración de sistemas eléctricos y de comunicación., s.f.). Los suelos son según la carta de suelos del Ministerio de Agricultura Ganadería y Alimentación (MAGA) Andisoles, Entisoles y Alfisoles (10-2002).

\section{Donde:}

"Los entisoles son, de todos los suelos, los que menos han tenido influencia de los factores formadores puesto que aún no se han desarrollado los cambios necesarios para la formación del suelo. (Ibáñez Asensio, et al., s/f) Sin embargo no es el equivalente a un suelo rocoso. Está vivo y pulverizado y tiene color oscuro.

Esta novedad del suelo sin perfiles responde muy bien a la particularidad de la agricultura en la región. La precipitación por su parte tiene efecto en la condición de los entisoles hay movimiento descendente constante de materiales por gravedad y por las aguas y recambio de nutrientes minerales para las plantas.

\section{Metodología aplicada al estudio de datos satelitales}

Los datos masivos hoy día ofrecen la posibilidad de evaluar deforestación y conservación en forma inmediata y de fácil acceso (Hansen, 2013) estos datos de la misma manera se dan a conocer mediante la Universidad de Maryland (University of Maryland, 2013). Nuestro estudio explora la escala regional y la local con una perspectiva diacrónica e interdisciplinaria. Los cambios en la vegetación se ubicaron en la historia reciente en la Región. El porvenir de la vegetación se considera parte de la historia humana. Los datos son entonces usados con otra perspectiva y pueden diferir de lo presentado por los datos masivos. 
En las escalas regional y local, usamos imágenes Landsat cortesía de USGS de la NASA, gobierno de los Estados Unidos de América. De cada una se seleccionaron dos bandas, destinándose un primer grupo de datos a un análisis, que mostrara una sola secuencia en el tiempo de los cambios y la guerra empezando por 1979. En este segundo análisis que estamos presentando aquí tomamos dos grupos de datos, series provenientes de 2 índices para todas las fechas.

Estas imágenes fueron seleccionadas por su calidad porque en ese momento no tuvieran nubes y sí contaran con datos completos o recuperables. Pero aparte se tenía que resolver una pregunta muy importante. ¿Cómo hacer comparables imágenes que con el paso de los años han cambiado, con los avances tecnológicos? De principio parece que con hacer el mismo tratamiento en todas está resuelto. No fue así. Un largo camino de tratamientos que cada vez arrojaban diferencias y errores como la acumulación de los datos en una sola parte del histograma o histogramas muy atípicos, nos llevaron a hacer más selecciones y a comprender cómo es que se comportaban las imágenes con los diferentes softwares, con la condición previa de no perder datos con los tratamientos.

Todo esto nos arrojó una serie de imágenes con las que ya era posible trabajar desde 1973 a 2016.

De estas imágenes se obtiene el NDVI que se usa para nuestro trabajo de seguimiento en estos años y especialmente en los años de la guerra.

La vegetación activa se calcula con una división que usa dos bandas de la imagen satelital, del rojo, para medir la absorción diferenciada que hace la clorofila e Infrarrojo cercano (NIR) que muestra la estructura y actividad de la planta. Si es más joven refleja más NIR (Fernkunde Lexikon, 2019).

\section{Banda}

Roja: “...parte roja de la luz visible de la longitud de onda entre $0.63 \mu \mathrm{m}$ y $0.69 \mu \mathrm{m}$, en resolución de $30 \mathrm{~m}$.

Infrarroja: Luz rebotada en el campo del infrarrojo cercano, en el campo de la longitud de onda entre $0.7 \mu \mathrm{m}$ y $1.3 \mu \mathrm{m}$ con resolución de $30 \mathrm{~m}$ en la fuente de datos original.

\section{Función}

Mide la absorción diferenciada de clorofila de las diferentes especies de plantas; sirve para diferenciar entre tipos de plantas así como distinguir tipos de suelo, contenido mineral.

Infrarrojo cercano mide la actividad de la plantas; mientras más joven sea la planta, reflejará más infrarrojo. También puede verse el estado de las células vegetales. NIR proporciona mucha información."

Figura 3. Bandas usadas de imágenes Landsat

(Fernkunde Lexikon, 2019) (trad. Martha E. Villavicencio E). 
EI NDVI se calcula con una división sencilla que se puede hacer mediante el uso de software, resultando de ella una imagen. Pudimos observar solamente algunos cambios de rango de lo considerado para $R$ y NIR en el tiempo; así como cambios en los números de banda correspondiente a los rangos para R y NIR.

$$
N D V I=\frac{N I R-R}{N I R+R}
$$

\section{Donde:}

NIR= Infrarrojo cercano (por sus iniciales en inglés)

\section{$\mathrm{R}=$ Rojo}

EI NDVI está comprendido entre los valores de -1 y 1 , mientras que la vegetación activa estará en el rango de 0.2 a 1 . Para los siguientes pasos de la metodología se usó la normalización de 0 a 255, que son los tonos de gris visibles en la pantalla. Se hizo un procesamiento especial a causa del cambio en los bits de las imágenes actuales de Landsat 8 (Parrot, 2018) (Parrot, 2018) y corrección de sobreconteo de pixeles en el perímetro de nuestro corte (Binar_V3: Parrot; Mayo 2019). Después hicimos una segunda secuencia con datos de 154 a 255, valores más álgidos para encontrar la vegetación más activa.

Una vez obtenidos estos datos se armó la secuencia de imágenes del periodo estudiado. La binarización (Parrot, 2018) posibilita contar las hectáreas por NDVI, para poder comparar por año. A continuación proporcionamos un ejemplo del procesamiento efectuado para cada imagen hasta llegar a su binarización que nos permite contar hectáreas.

\section{Tratamiento para 1986}

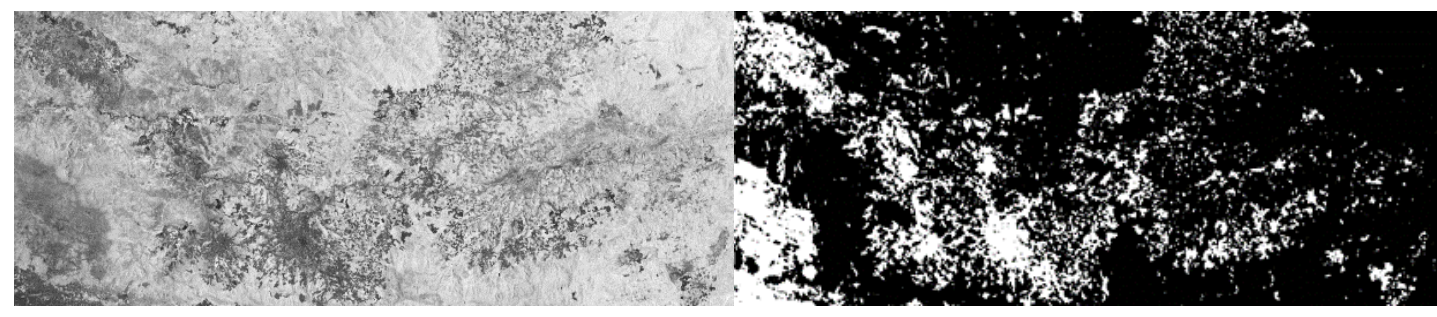

ivinuyu

76.31

23.69

Imagen: LT50200491986104XXX15 "Image courtesy of the U.S. Geological Survey" row path 2049 Landsat 5 TM. Bandas 3 (R) y 4 (IR) para obtención de NDVI 128-255, los valores se extraen hacia un histograma. Finalmente se binarizó la imagen y se obtienen porcentajes y hectáreas ocupadas por vegetación activa, todo mediante software descrito en materiales. Elaboraron Martha E. Villavicencio y Jean Francois Parrot con los softwares mencionados en texto.

Figura 4. Ejemplo del procesamiento para el año 1986 


\section{Otra secuencia: la historia regional}

Nuestra secuencia que se empata a la de los cambios en las tierras de cultivo y los bosques de la región, en un conflicto armado que dura 36 años, cuando el gobierno guatemalteco extermina comunidades indígenas completas, con un motivo formal que fue la lucha contra la guerrilla, pero que se operó como exterminio de la población indígena.

Como en otros países de la región, los pueblos indígenas guatemaltecos han vivido discriminados y explotados, las personas de piel blanca han sido dueñas de medios de producción, han controlado la política, y se han hecho históricamente propietarios de las tierras agrícolas.

Las huellas de la colonia se hacen perceptibles en la distribución de la tierra. Para el siglo XIX la Reforma Liberal puso grandes extensiones en manos alemanas y compañías de los Estados Unidos, tierras comunales se vuelven baldíos y tierras nacionales para subastarlas para 1871 (Ramírez García, 2009). Las plantaciones comerciales hasta arreglan fincas como si fueran Suiza o Alemania en las montañas que habitaban los mayas.

Los terratenientes obtenían riqueza de los productos agrícolas de exportación con mano de obra indígena mal remunerada mantenido el orden con violencia y asegurándose el poder político (Castillo, et al., 2011). Una de las transformaciones más fuertes en favor de la población fue el Decreto 900 de Reforma Agraria de 1952, que beneficia a 500000 campesinos. La contra-reforma en 1954 tras un Golpe de Estado lleva a la devolución a de entre el 80 y $90 \%$ de las tierras repartidas a los terratenientes (Ramírez García, 2009). La Reforma del gobierno de Jacobo Arbenz Guzmán (1951-1954) fue afectada por los intereses económicos. Una visión racista de que las tierras indígenas están desocupadas y ociosas y los pueblos indígenas no son merecedores de esos espacios se volvió a imponer.

La organización campesina y popular había madurado mediante prácticas de capacitación campesina y defensa de los derechos agrarios, a pesar de las agresiones. Para 1972 se habla del surgimiento del Ejército Guerrillero de los Pobres, EGP en la región.

La guerrilla crece y se diversifica, en la idea de llegar al poder y cambiar el orden económico en Guatemala. La represión acompaña este proceso y va contra toda forma de organización campesina e indígena con fuerzas militares, paramilitares y policiales (Ramírez García, 2009, pp. 152-153).

El gobierno guatemalteco y el ejército responden con campañas de exterminio. La represión fue directamente contra sindicatos, gremios, ocupaciones de tierras y como una forma de impedir la sublevación contra la oligarquía local (Castillo, et al., 2011)El pueblo Ixil fue entonces uno de los objetivos de la guerra del gobierno guatemalteco, que asesina miles de personas hasta poco después de la firma de los Acuerdos de Paz en 1996.

Bajo el régimen del presidente Romeo Lucas García en 1981 el ejército guatemalteco creó una fuerza auxiliar de carácter paramilitar, las Ilamadas Patrullas de Autodefensa Civil (PAC). A mediados de esa década las PAC llegaron a contar con unos 900000 campesinos indígenas de 15 a 60 años que se convierten en un brazo represor del Estado. Cuando se desactivan con los Acuerdos de Paz en 1996 las PAC contaban en sus filas unas 400000 (Hemeroteca Prensa Latina, 08-08-2017) Las PAC masacraron población y ejecutaron las órdenes de vigilar las comunidades y perseguir y asesinar a quienes en un régimen de 
guerra les pareciera enemigo, lo que abre un espectro muy amplio. Ejecutaron junto con el ejército masacres de población indígena, ocuparon tierra como premio a su cooperación y destruyeron propiedad de otras personas.

El dominio territorial de los militares y los gobiernos en guerra contra los indígenas también restringió los desplazamientos de los habitantes de Quiché, y obligó a las personas a vivir en las partes más bajas, creando asentamientos llamados Aldeas Modelo reunidas en Polos de desarrollo.

El 3er Informe de la Comisión Interamericana de Derechos Humanos de 1985 (CIDH-OEA, 03-10-1985) consigna datos de bombardeos, saqueos, quema de parcelas, concentraciones forzosas de población en polos de desarrollo.

En datos de la Agencia Internacional para el Desarrollo de 1984, ya había 175000 personas despojadas de su hogar en el Departamento de Quiché. En nuestro corte de estudio había uno de los denominados Polos de Desarrollo, llamado Triángulo Ixil.

El Polo de desarrollo juntaba varias poblaciones que vivían adentro en estado de sitio y suspensión de garantías (CIDH-OEA, 03-10-1985, p. cap.3) Los polos de desarrollo estaban bajo el mando del Estado Mayor de la Defensa Nacional y obedecían a fines militares, aunque el discurso gubernamental incluía asistencia a desplazados de guerra.
Los Polos de desarrollo estaban en las partes que no tenían las mejores tierras, y se prohibía a las personas ir a sembrar su propio maíz o vivir en las viviendas de las montañas. Podemos con seguridad plantear que el mosaico agrícola y de bosques fue modificado radicalmente en estos años. Que el paisaje cultural fue modificado dando lugar a asentamientos donde concentraban a la población indígena constantemente vigilada; y tenían que trabajar, delatar, perseguir, matar, según consideraba el ejército esas necesidades. Las personas no podían irse a sembrar sus alimentos.

México recibió hasta 1984 unos 45000 refugiados que ya podían ser reconocidos con esta condición (Kauffer, 2000). El retorno organizado empieza en 1990 y muchas personas retornan hasta 1993 con acompañamiento internacional. Las poblaciones escondidas en las montañas donde actualmente está Visis Cabá (ver mapa) entre otros lugares, soportaron 14 años comiendo lo que pudieron del bosque.

Podríamos suponer que ante el abandono de las tierras de cultivo tendríamos un ascenso en la vegetación en general, porque podía crecer sin impactos antropogénicos. Pero nuestros datos apuntan a que los años de la guerra van a significar un descenso en toda la vegetación incluida la natural. Esto no es solamente un dato de coincidencia. Es porque el pueblo ixil tiene tanto una parcela diversa como uso cultural del bosque. 


\section{Resultados}

A continuación presentamos el análisis de una de las secuencias de datos que es la de la vegetación para proceder a la interpretación de los datos.

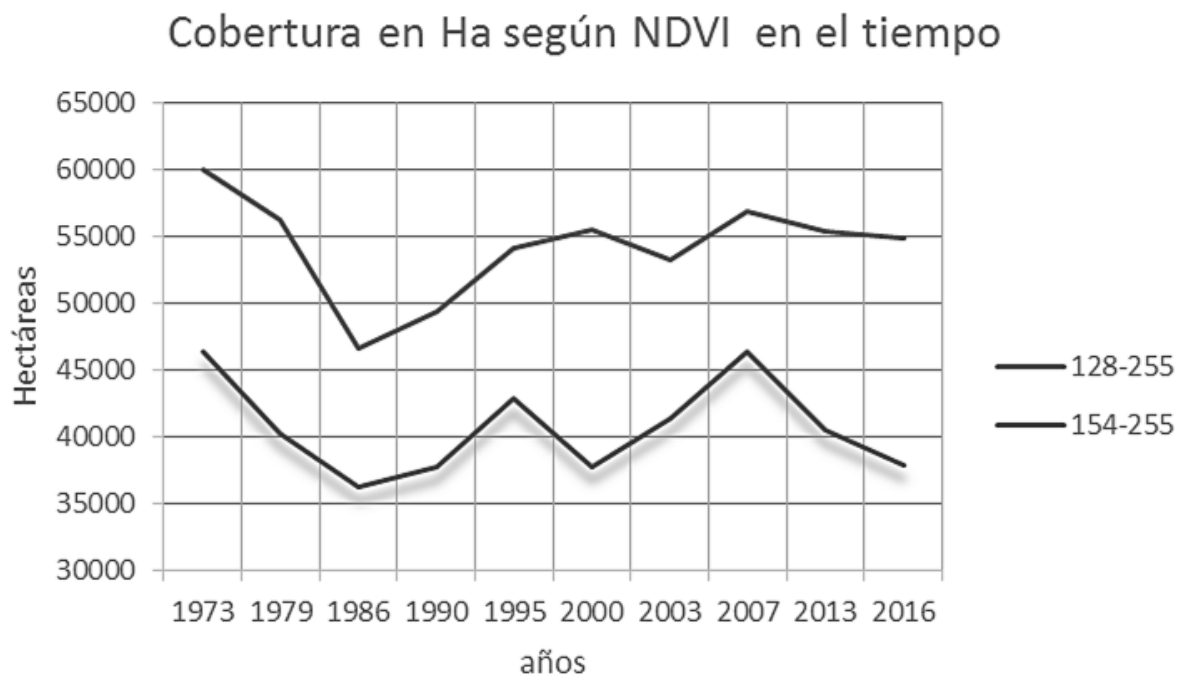

Figura 5. Dos series de datos sobre la vegetación

En los resultados obtenidos tras procesar imágenes Landsat desde 1973 hasta 2016 y obtener los NDVI y sus histogramas podemos encontrar cambios en la vegetación que pueden ser interpretados con los datos históricos de la región, que tiene cicatrices de la guerra por afectaciones a la propiedad de la tierra; concentraciones forzadas de población indígena por parte del gobierno del país, para poderla controlar y apartar de los movimientos agrarios y especialmente de la guerrilla; masacres y destrucción de las parcelas de la población Ixil que habita nuestro corte del estudio.

Las transformaciones entonces tienen una relación con las condiciones impuestas por la guerra. La construcción de infraestructura es un potencial actual, por otra parte, para generar claros, que además no volverán a llenarse de plantas, como es el caso de la Termoeléctrica Palo Viejo I, ubicada $6 \mathrm{~km}$ al Este de nuestro corte, de hecho, se perciben algunos claros que pueden explicarse haciendo un corte mayor hacia el Este, aunque lo que aquí se valora es la permanencia de vegetación activa.

En los años de construcción y de que empieza a caminar la Hidroeléctrica en 2009 podemos observar diminución en la capa de vegetación más activa de 154-255 y en la general 128255 hacia los valores del final de la gráfica.

\section{Discusión}

El cambio en la vegetación que muestran nuestros resultados proviene de los movimientos dentro del territorio que afectaron directamente a los asentamientos ixiles en la zona del conflicto armado, como es posible verificar en la data relativa a las órdenes de exterminar, asesinar, destruir tierra y parcelas, con la intención de exterminar población del gobierno de Guatemala en los años setenta y ochenta, tomando como motivo la guerra contrainsurgente. 
En otra dirección los cambios se dan hacia la recuperación de la vegetación, con la disminución de las agresiones y principalmente con el regreso de la vida cotidiana y agricultura de la población Ixil. Aunque la vida cotidiana actual es todavía un contexto de discriminación y desposesión de los pueblos indígenas en el país.

A pesar de las concentraciones de población y de que fueron desposeídas de sus tierras o asesinados, con el cese de las acciones militares masivas y directas la vegetación tiene cambios, mostrando más actividad y recuperación tanto en la cantidad de hectáreas ocupadas, como en la cualidad de la vegetación.

La cualidad es un problema que se deja sin abordar más profundamente porque es necesario un trabajo posterior que partiendo de los datos obtenidos, pueda verificar y distinguir entre la vegetación más vieja y estructurada y la nueva que en muchos casos sería vegetación secundaria. Nuestros datos sugieren que ambas vegetaciones van juntas y que el uso campesino ixil de la tierra da lugar a una conservación y reposición de la vegetación en su conjunto al firmarse la paz en el país.

Asimismo la vegetación más activa se recuperó con el retorno de la población a sus lugares de origen. La reposición de la capa más activa de la vegetación ha tenido recaídas en los años en que entra la infraestructura y hacia la actualidad, mientras que muestra picos en ascenso en los años del retorno organizado y hacia 2007.

\section{Referencias}

Bouroncle, C. y otros, 2015. La agricultura de Guatemala y el cambio climático ¿Dónde están las prioridades para la adaptación?,
Guatemala: CGIAR; CCAFS; CATIE; Conservación Internacional; Regatta.

Castillo, M. Á., Toussaint, M. \& Vázquez, M., 2011. Historia de las relaciones internacionales de México 1821-2010. Centroamérica.. 1a. Volúmen 2. Coordinado por Mercedes de Vega ed. México, D.F.: Secretaría de Relaciones Exteriores.

CIDH-OEA, 03-10-1985. Informe de país. Tercer informe sobre la situación de los Derechos Humanos en la República de Guatemala, Washington D.C.: Organización de Estados Americanos.

Empresa Propietaria de la Red; Integración de sistemas eléctricos y de comunicación., s.f. 6. Descripción del Medio Ambiente.. [En línea] file:///E:/libros_inter\%C3\%A9s/ geologiaGuate.pdf

Fernkunde Lexikon, 2019. www.fe-lexikon. [En línea] www.fe-lexikon-khtm\#kanal

Hansen, M. C. H. P. V. P. R. M. e. a., 2013. High-Resolution Global Maps of 21st-Century Forest Cover Change. Science 15 Nov 2013: Vol. 342, Issue 6160, pp. 850853 DOI: 10.1126/science.1244693. , pp. 850-853.

Hemeroteca Prensa Latina, 08-08-2017. 1996: desmovilización de las Patrullas de Autodefensa Civil, Guatemala: Agencia Prensa Latina.

Ibáñez Asensio, S., Gisbert Blanquer, J. M. \& Moreno Ramón, H., s/f. Entisoles, Valencia, España: Unidad Politécnica de Valencia.

INCA Rural, 1982. Diccionario Agropecuario de México. 1a ed. México: Instituto Nacional de Capacitación del Sector Agropecuario, A.C.

Instituto Nacional de Sismología, vulcanología, meteorología, e hidrología de Gua- 
temala, s/f. Atlas hidrológico. [En línea] http://www.insivumeh.gob.gt/hidrologia/ ATLAS_HIDROMETEOROLOGICO/ Atlas_hidro.htm

Kauffer, E. F., 2000. Refugiados guatemaltecos en México: del refugio a la repatriación, del retorno a la integración.. Boletón editado por el Consejo Nacional de Población, n.12(año 4), pp. 7-12.

MARN, 2017. Informe ambiental del Estado de Guatemala, Guatemala: Ministerio de Ambiente y Recursos Naturales; PNUD.

Ministerio de Agricultura, Ganadería y Alimentación, 10-2002. Mapa de clasificación taxonómica de suelos. Guatemala: PEDN-MAGA Gobierno de Guatemala.

Organización de Estados Iberoamericanos para la educación, la ciencia y la cultura, $\mathrm{s} / \mathrm{f}$. Informes sobre los sistemas nacionales de cultura. Guatemala. [En línea] https://www.oei.es/historico/cultura2/ Guatemala/presentacion.htm

Parrot, J.-F., 2011. Software Pins_V2. Número de certificado INDA (Instituto Nacional de Derecho de Autor): 03-2011-120112060000-01.

Parrot, J.-F., 2011. Software Extract_V2. Número de certificado INDA (Instituto Nacional de Derecho de Autor): 03-2011-120112005800-01.

Parrot, J. F., (2011). Software Binar_V2. Número de certificado INDA (Instituto Nacional de Derecho de Autor): 03-2011120112041501-01. Actualización 2018 Binar_V3 [en linea]] parrot@igg.unam. $\mathrm{mx}$

Parrot, J.-F., 2014. Software Índices_V2. Número de certificado INDA (Instituto Nacional de Derecho de Autor): 03-2014-022712173900-01.
Parrot, J. F., 2018. TIF-extract-exe. [En línea] Ramírez García, L. R., 2009. Criminalización de los conflictos agrarios en Guatemala. Revista Análisis político. Seguridad y justicia. Pilares de la democracia., pp. 129-168.

Saubes, N., Gálvez, J., Pérez, G. \& Gándara, A., 2015. Balance hidrológico de las subcuencas de la República de Guatemala. Bases fundamentales para la gestión del agua a largo plazo., Guatemala: Instituto de Agricultura, Recursos Naturales y Ambiente de la Universidad Rafael Landívar de Guatemala.

Sichar, G., s/f. Guatemala, el genocidio escondido. [En línea] www.albedrio.org

Sistema de las Naciones Unidas en Guatemala, 2014. Guatemala: análisis de la situación del país. Guatemala: Common Country Assessment, Guatemala.: Sistema de las Naciones Unidas en Guatemala.

University of Maryland, 2013. University of Maryland, Global Forest Change. [En línea] https://earthenginepartnersappspot.com/science-2013-global-forest 


\section{Sobre autora}

\section{Mtra. Martha Eugenia Villavicencio Enríquez}

Licenciada en Geografía (UNAM), licenciada y Maestra en Pedagogía (UNAM); Doctorante en Estudios Latinoamericanos en la UNAM. Ha hecho traducción del alemán y comunicación. Capacitadora en temas ambientales con comunidades y mujeres indígenas y campesinas. Profesora del posgrado en educación intercultural de la Universidad Marista.

\section{Sobre coautores}

\section{Dr. Jean Francois Parrot}

Licenciado en Ciencias de la Tierra por la Universidad de Paris Sorbonne en 1963. Obtuvo el título en Arqueología prehistórica y Etnografía en la Universidad de Paris en 1967. También en 1967 se doctoró en el Doctorado de Tercer Ciclo, en Petrografía Universidad de Paris Sorbonne. En 1974 se doctoró en Petrología por la Universidad de Nancy. Es investigador en el Laboratorio de Análisis Geoespacial del Instituto de Geografía de la UNAM y trabaja en los temas de Modelos Digitales de Terreno (MDT); Percepción Remota (PR); Parámetros morfológicos, modelación y simulaciones y en Dimensión fractal aplicada al estudio de los paisajes y del espacio urbano; así como en el Desarrollo de algoritmos y Software. Ha escrito numerosos artículos científicos y ha participado en varios libros y manuales, creador del software Tlaloc y del Frog, entre otros.

\section{Dr. Mario Vázquez Olivera}

Licenciado en Historia, Maestro y Doctor en Estudios Latinoamericanos por la Universidad Nacional Autónoma de México. Investigador en el Centro de Investigaciones sobre América Latina y el Caribe de la UNAM en los temas de Historia sociopolítica de Centroamérica y Chiapas durante el siglo XIX; Historia de la Frontera Sur y de las relaciones México-Centroamérica; y guerra y cambio político Centroamérica durante la segunda mitad del siglo XX. Es tutor y profesor del posgrado en Estudios Latinoamericanos de la UNAM y dirige el seminario Democracia y guerra en Centroamérica. Autor de artículos científicos y libros.

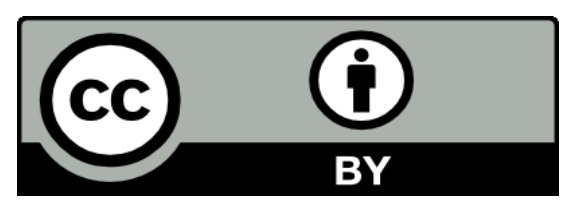

Este texto está protegido por una licencia CreativeCommons 4.0.

Esta licencia permite que otros distribuyan, mezclen, adapten y desarrollen su trabajo, incluso comercialmente, siempre y cuando le den crédito por la creación original. 